\title{
Perceptions of and Actions toward Unproductive and Deleterious Faculty
}

Shane Desselle, $\mathrm{PhD}^{1}$; David Zgarrick, $\mathrm{PhD}^{2}$; Sujith Ramachandran, $\mathrm{PhD}^{3}$

${ }^{1}$ Touro University California College of Pharmacy

${ }^{2}$ Northeastern University Bouve College of Health Sciences

${ }^{3}$ University of Mississippi School of Pharmacy

\section{Abstract}

Background: Academic deadwood is a term used to describe certain faculty whose behaviors are counter to the organization's goals. Little is known about those behaviors and aspects of performance considered most problematic, nor how academic pharmacy is addressing the issue of these faculty.

Objectives:(1) Ascribe the salience of various factors in defining deleterious, or so-called "deadwood" faculty and determine differences in these perceptions according to faculty institution, rank, discipline, years of experience, and other personal and work-related factors; (2) identify perceptions of what is currently done and what should be done in response to these faculty; and (3) discern differences among faculty and administrators in these perceptions.

Methods: The study utilized a web-based survey of U.S. faculty in colleges/schools of pharmacy delivered to a census sample of 3378 members within 2018 AACP list-servs. Items were developed from the literature with the express intent of measuring various aspects of academic deadwood pertaining to the study objectives. Reminders were employed to maximize survey responses. Frequency distributions and chi-square statistics were conducted to describe the data.

Results: The research found poor quality of teaching, poor citizenship behaviors, and lack of scholarly publications to be defining of deadwood. Responding faculty believed that there should be attempts to develop and rejuvenate these faculty, but also disciplinary actions and termination in some cases. The research identified a significant gap between the frequencies of actions currently being taken in response to these faculty versus the frequency with which actions should be taken. While there were differences of opinion in describing and recommending frequency of action in response to these faculty, respondents from different types of institutions and holding different administrative appointments and rank were largely in agreement.

Conclusions: There was general agreement among faculty in varying positions, including supervisory ones, at different types of institutions on what is currently being done and what should be done in regard to deadwood faculty. The paper discusses implications for communication and academic governance, even within the boundaries of policies, rules, and regulations at the larger, institutional level.

Keywords: faculty, deadwood, productivity, collegiality, academic governance

\section{Introduction}

Faculty employed by institutions of higher learning face increasing demands for productivity in research and scholarship as well as for teaching outcomes. ${ }^{1}$ Additionally, some faculty in health professions programs also provide clinical service to patients, ${ }^{2}$ adding further to work burden and stress. ${ }^{3}$ These heightened expectations are part of evolution in higher education, where change and change management have become part of the daily lexicon. These changes include, but are not limited to scarce funding and resources, changing demands for learning among students, shifts in technology, and a shrinking number of faculty tenured or on tenure-track. ${ }^{4} A s$ such, the importance of organizational culture in academic settings and its effect on faculty are coming more clearly into focus. ${ }^{5}$ Part of what denotes productivity transcends teaching and scholarship, and includes an aspect of collegiality. ${ }^{6}$

Corresponding author: Shane Desselle, PhD

Professor

Touro University California College of Pharmacy

Email: sdesselle68@gmail.com
With the expectation that faculty be productive in intra-role (contractual, e.g., teaching, scholarship, service) as well as extra-role (e.g., citizenship, volunteerism, professional manners, courtesy) aspects of their job, some of them will invariably fall short of expectations. Consistently low performers in what might be several of these areas have been referred to as "academic deadweight" or "academic deadwood". 7Deadwood is a term that has been around for decades. McCarty (1993) pointed to deadwood as those "exhibiting burnout in their behaviors and lack of productivity ... though attitudinal factors and not just burnout may be at play". ${ }^{8}$ Similarly, Allen (2009) described deadwood nursing faculty as those who not only fail to add, but might also detract from the goals of the organization and its composite employees. ${ }^{9}$ Ina study employing a focus group of deans from U.S. pharmacy programs, Desselle and Zgarrick(2020) identified elements that these administrators used to describe deadwood faculty. ${ }^{10}$ The deans emphasized a lack of citizenship and made it a point to distinguish those persons they considered "toxic" versus "merely unproductive". The deans indicated that having even just 1-2 toxic individuals were more problematic than having a number of unproductive faculty. Their views would 
appear to corroborate other literature lamenting deleterious behaviors of faculty, principally those who are recalcitrant and who refuse the obligation of being good followers, even to the best of leaders. ${ }^{11}$ The presence of many such individuals is stated to create a toxic environment built upon rigid, aggressive, and narcissistic behaviors. ${ }^{12}$

\section{Study Purpose/Objectives}

It would be beneficial to acquire perspectives among faculty and administrators to discern how they perceive such faculty. There are also benefits in understanding whether perceptions of these faculty differ between faculty and administrators from various types of institutions and different areas of expertise. Such information can help identify gaps in these perceptions and thus build bridges to enable better communication, governance, and managerial policy. The objectives of this study were to: (1) ascribe the salience of various factors in defining deleterious or so-called deadwood faculty and determine differences in these perceptions according to faculty institution, rank, discipline, years of experience, and other personal and work-related factors; (2) identify perceptions of what is currently done and what should be done in response to these faculty; and (3) discern differences among faculty and administrators in these perceptions.

\section{Methods}

\section{Study Design/Sample}

Investigational Review Board (IRB) approval for the study was sought and deemed to be exempt by the primary author's institution. The study employed the use of a questionnaire survey in a cross-sectional design. Email list-servs were purchased from the American Association of Colleges of Pharmacy (AACP). The lists included deans and department chairs from all US schools of pharmacy, as well as individual faculty belonging to AACP's discipline-based academic sections. After removal of duplicate entries from the lists, 3,378 unique deans, department chairs, and non-administrative faculty comprised the census population for inclusion in the study.

As recommended by Dillman et al. (2009) to maximize survey responses, sampled recipients received an initial email on May 6, 2019 notifying them of the upcoming survey. ${ }^{13}$ This was followed on May 13 by an email with a link to the survey built in Qualtrics ${ }^{\circledR}(2019),{ }^{14}$ then followed by 3reminder emails approximately 7days apart. The survey was closed on June 10.

\section{Questionnaire Survey}

The survey consisted of several components, the first of which sought to discern the extent to which various behaviors are indicative of deleterious faculty, so dubbed as "academic deadwood" in the survey. The next component asked respondents to provide an assessment of the frequency in which various actions were taken by their institution in response to deadwood faculty, including: attempts to develop/improve them, disciplinary actions, withholding salary increases, and reassigning their work activities. These questions were followed by similar questions on the same potential actions, except that respondents were asked what they think SHOULD be done in response to these faculty. Respondents were also asked who was involved in taking action with regard to these faculty at their institutions

\section{Pre-Testing}

The questionnaire was reviewed by 8 pharmacy academicians for its content, instructions, and flow, including suggestions on items to include as potential actions/behaviors to add for consideration as factors to describe a deadwood faculty member. The academicians were known to the investigators as being leaders in academic pharmacy from various disciplines, varying by gender, academic rank, and length of service, and from varied types of institutions, some of whom with expertise in survey methodology. The effort was convened as an asynchronous discussion through email over the course of several days until everyone was satisfied with the content of the questionnaire.

\section{Data Analysis}

Data were imported from Qualtrics (C) into SPSS, v.25 (IBM, $2017)^{15}$ for analysis. Frequency distributions and percentages were calculated for each item. For several demographic variables, categories of data were combined to improve the clarity of the analysis and avoid empty cells, including variables related to institute type, faculty discipline, and length of service (see Tables). Nonparametric statistical tests (Mann-Whitney U and Kruskall-Wallis) were performed to compare groups on responses to the activity/behavior variables, all of which were measured on ordinal scales.

\section{Results}

\section{Questionnaire response and respondent characteristics}

Out of 3,378 surveys distributed, there were 29 returned as undeliverable or with error messages. There were568 survey responses initiated, with 463 completed in their entirety and available for analysis. This yields a usable response rate of $13.8 \%$ and a survey completion rate of $81.5 \%$, both of which compare favorably with web-based surveys of academic and health professionals. ${ }^{16}$ Descriptive statistics of respondents and their employing organizations are provided in Table 1. Respondents represent a broad array of positions and types of institutions, not unlike what can be found comprising AACP's general membership, ${ }^{17}$ although respondents to the current survey had greater numbers of respondents who belong to social and administrative sciences and to pharmacy practice (thus fewer on basic sciences), as well female respondents.

\section{Describing deleterious/deadwood faculty}

Table 2 provides responses to item questions seeking perceptions of what constitutes deadwood faculty. This section of the results does not address the results of any statistical tests; rather, it highlights some general, or descriptive findings. Respondents "very much" agreed that low quality of teaching (79.5\%) and poor collegiality/citizenship behaviors $(76.0 \%)$ 
were indicative of what they considered to be a deadwood faculty member. Respondents also "very much" agreed that a low quantity of teaching (68.0\%) and failure to effectively participate in institutional committees $(61.8 \%)$ were indicative of a deleterious faculty member, but to a somewhat lesser extent than the quality of teaching and collegiality/citizenship. There was less agreement as to whether conducting little/no scholarship (47.3\%) and failing to engage in external professional/scientific communities (39.7\%) was indicative of being considered deleterious. Respondents from research institutions, those tenured or on tenure track, and those who supervise other faculty were more likely to indicate low productivity in scholarship as being descriptive of being deleterious. Almost $80 \%$ of respondents very much considered low quality teaching to be indicative of being described as deleterious, with respondents from private institutions, those employed by an institution with a teaching mission, and those in pharmacy practice most likely to feel this way.

Respondents who were more likely to indicate lack of participation on institutional committees as being descriptive of deleterious were those who were tenured, and those with over 20 years of experience. Those who supervise other faculty and those over 20 years of experience were more likely to indicate lack of engagement with external communities as being descriptive of deleterious faculty. Over $75 \%$ of respondents considered lack of collegiality as very much descriptive of deleterious faculty, and particularly those from private institutions and institutions with a teaching-based mission.

Over $65 \%$ of respondents agreed that a faculty member must be poor in at least two of the three intra-role aspects of their jobs (teaching, scholarship service) for them to describe that colleague as "deadwood". Over $80 \%$ of the respondents felt that they had at least one deadwood colleague in their school/college of pharmacy, with close to $50 \%$ of respondents indicating that they had 2-3 such colleagues. Respondents in the social and administrative sciences and pharmacy practice disciplines were more likely to indicate that they had deadwood colleagues than those in other disciplines.

\section{Actions regarding deadwood faculty}

Table 3 provides respondent perceptions of faculty about what is currently being done and what should be done in regard to deleterious faculty at their institutions. Provided here is a summary of key findings of statistical differences. Over $80 \%$ of respondents indicated that there should be efforts made by their programs to develop such faculty; however, only about $25 \%$ indicated that this was currently being done on a routine basis. Respondents from pharmacy practice were more likely to indicate that developing these faculty should be done on a routine basis. Respondents at teaching-oriented institutions were more likely to indicate that efforts to develop deadwood faculty were not being done on a routine basis. There were $12.1 \%$ of respondents who indicated that providing no salary increases for deadwood was done routinely, although $38 \%$ of respondents indicating not knowing or being unsure whether this was practiced at their organization. Over half of respondents indicated that providing no salary increases was a measure that should be undertaken routinely, particularly those at research/balanced mission institutions, those who are tenured, and those who supervise other faculty.

Fewer than $20 \%$ of respondents were aware of removing administrative titles for deleterious faculty being done occasionally or routinely at their institution. On the other hand, approximately $3 / 4$ of them stated that this should be done at least occasionally, if not routinely. There were only $4.1 \%$ of respondents who indicated that progressive discipline was performed routinely. Between $1 / 3$ and half (over $40 \%$ ) of respondents indicated that progressive discipline should be a tool used routinely in response to deadwood faculty. Respondents from private institutions and those who supervise faculty were more likely to indicate that termination was something being undertaken at least on occasion. Over $60 \%$ of respondents indicated that deleterious faculty should be encouraged to leave the institution. There were fewer than 1 in 5 who indicated that this was at least occasionally being done, with greater likelihood being indicated by respondents from research/balanced, versus teaching institutions.

Department chairs and School Deans were the most likely to be involved in taking actions regarding deleterious faculty in their units, with over three-quarters of respondents indicating that these administrators are at least somewhat or very much involved in taking actions involving deadwood faculty. On the other hand, there was a general perception by respondents that the faculty colleagues and peers of deleterious faculty are not involved in taking actions regarding their colleagues, with almost $90 \%$ indicating that faculty colleagues and peers have little (34\%) to no (54\%) involvement in these matters.

\section{Discussion}

This study evaluated factors that academic pharmacy faculty use to describe what they would refer to as being deleterious or "academic deadwood". While marginal productivity in scholarship and quantity of teaching played a role, respondents indicated that poor teaching quality and poor collegiality/citizenship behaviors are quite descriptive of deleterious faculty. There were statistical differences in perceptions among various groups in how they describe academic deadwood. Those who supervise other faculty and those in pharmacy practice placed even more emphasis on poor teaching quality and poor collegiality.

However, while achieving statistical differences, the ratings of these attributes (poor teaching quality, poor collegiality) was consistently high and more indicative of describing deleterious faculty, in general, than volume of teaching, scholarly productivity, and engaging external communities. The research also demonstrated that there are gaps between what 
respondents perceive is currently being done versus what should be done, with many respondents indicating that some of the measures proposed (e.g., discipline and termination) should be employed more routinely than they perceive that they are currently being used. Toma (2007) discussed structural issues and communication processes affecting academic governance; structural issues include changes in administrative appointments, organizational rewards, and appointment types, whereas communication processes involve real and symbolic gestures aimed to improve organizational effectiveness that include actions taken to ensure faculty equity and mutual accountability, which include issues around unproductive and non-collegial members. ${ }^{18}$ Sorinola et al. (2015) argue that true reform and development come only when faculty are engaged, which includes not only having participatory governance, but also use of effective communication by supervisors to mitigate ambiguous policies and actions. ${ }^{19}$

The research findings corroborate and should be taken into context with other research on faculty productivity, collegiality, and academic institutional governance. Evidence suggests that any negative impact of merely unproductive faculty is outweighed by the positive impact of "stars" and topperforming researchers at an institution. ${ }^{20}$ Yet, it is also suggested that the presence of more deleterious, toxic, or deadwood faculty can do significant harm to the organization by setting a poor example, affecting the organization's/department's culture, and even stifling growth or resisting needed and inevitable change. ${ }^{21}$

Nearly all respondents in the current research indicated that there should be frequent attempts to develop these. Given the importance placed on quality teaching, even in researchoriented institutions, suggestions by Nikolioudakis et al. (2015) would appear appropriate. ${ }^{22}$ They recommended that institutions employ more flexible human resources management and assign underperforming faculty with greater teaching loads but couple that with rewards and incentives for improved performance. Additionally, institutions might continue investing in teaching centers or similar types of programs, as what appears to have become more commonplace. Schumann et al. suggest that such centers not only enhance the value of faculty contributions but also have the potential to permeate the educational fiber of the entire institution. ${ }^{23}$

Development initiatives and academic management policies and procedures that focus on collegiality are especially important, which is to suggest broader mentoring than merely job-specific tasks; but rather, on more career, or even "wholelife" mentoring. ${ }^{24,25}$ In doing so, institutions must define what collegiality is within their own context behaviors if they are to shape behaviors through policy, management, and reward systems. ${ }^{26}$ For example, the American Association of University Professors (AAUP) has expressed concern about the use of collegiality in faculty evaluations for fear of squashing respectable dissent and debate. ${ }^{27}$ Greater use of subjective criteria, such as collegiality, can be problematic for some individuals who do not curry favor with certain important individuals. Those subjective criteria could potentially be weaponized against them as might be the case for more vulnerable faculty, such as females and persons of color. Still, the emphasis to stress collegiality is important to deter deleterious individuals so as to promote positive climates in the academic program. ${ }^{28}$

Beyond development, respondents in the current research expressed a desire to more frequently deploy various actions against deadwood faculty, including more punitive ones. The inclusion of measures that can be viewed concurrently as developmental and punitive/correctional, such as additional committee assignments, is commensurate with recommendations for faculty throughout the life cycle of their academic career. ${ }^{29}$ The respondents' desire to see actions taken in handling deleterious faculty is commensurate with other evidence suggesting that faculty demand accountability and transparency. ${ }^{30}$ Transparency is likewise key to promoting perceptions of equity, as faculty believe that other members should be pulling their weight or face consequences. ${ }^{31}$

There were some differences between those who supervise versus those who do not supervise faculty in perceptions of what is currently being done about deadwood at their respective institutions. Yet, there were few statistical differences among these groups, considering all of the tests that were conducted between them seeking potential differences of perspective. This agreement would indicate that even those not in such positions are generally knowledgeable about the goings-on in this regard, despite some faculty admitting that they "do not know" what is being done.

There were differences across respondent characteristics and institution type. For example, there were some expected differences in faculty from public and research-oriented institutions in defining lack of scholarly productivity as deadwood, commensurate with faculty's work and attitudes about work at these types of institutions in the broader sense. ${ }^{32,33}$ The finding that fewer respondents from private institutions were aware of routinely used measures to address deleterious faculty could be indicative of the challenges faced by administrators and faculty at these institutions to more clearly articulate a mission of teaching versus research. ${ }^{34}$

Respondents in the current study recognized the department chair as integral to taking action regarding deleterious faculty. Much has been written about the role of department chairs, who advocate for faculty, yet help to administer organizational policy. The work of Gmelchand colleagues has advocated the need for chairs to be developed and mentored, themselves. ${ }^{35,36}$ It is understood that each individual faculty case of being unproductive, or especially deleterious, might involve cases of confidentiality; however, department chairs and other 
administrators can make expectations for productivity and collegial behaviors to faculty and the broader remedies sought by the institution when faculty are not meeting these expectations.

\section{Study Limitations}

Several limitations to the study must be considered. The study was conducted in one field: academic pharmacy. Faculty in other fields' disciplines might have responded differently. Yet, surveying faculty with backgrounds as disparate as bench chemistry, pharmaceutical engineering, sociology, economics, and clinical practice provides a great starting point for additional research. While the response rate was favorable compared to similar types of studies, a rate of return below $20 \%$ does not preclude selection bias wherein faculty currently involved or wanting to become more involved in academic governance would have been more likely to participate. There is little upon which to base any assessments of survey validity or reliability other than to suggest that respondents' answers were largely in the direction hypothesized. Also, the researchers made general inferences and describe gaps between what is currently perceived to be done versus what should be done. Some respondents admitted to not knowing what is being done in regard to deleterious faculty at their organization. After all, each individual brings forth a unique case, and some types of issues are confidential to all but certain members of human resources and to institutional administrators. Still, the lack of any large chasms between faculty with and without supervisory positions provides at least some measure of confidence in the results and their interpretation.

\section{Conclusion}

This study helped to clarify what is considered deleterious among faculty, or academic deadwood, with considerable emphasis placed on poor teaching quality and lack of collegiality. There were differences in perceptions of what is currently done versus what should be done to address these faculty across a variety of actions, particularly regarding the use of discipline and termination. These perceptions persisted even when comparing those in a supervisory position versus those who are not. Shared views between faculty and administrators might mitigate the challenges in taking steps in addressing these individuals to make for a more collegial and productive faculty.

Funding/Support: Internal funding from Touro University California College of Pharmacy (department funds, i.e., not an intramural grant)

Conflicts of Interest: None

Availability of data and material: Available upon request Authors' contributions: SD conceptualized the study and served as primary author of the manuscript; DZ assisted with methodological aspects, execution of the study, and editing of the manuscript; SR assisted with the data analysis plan and execution.

\section{References}

1. Mudrak J, Zabrodska K, Kveton P, Jelenik M, et al. Occupational well-being among university faculty: $A$ job demands-resources model. Res High Educ. 2018;59(3):325348. doi: 10.1007/s11162-017-9467-x

2. Holmes ER, Desselle SP. The use of speech disfluency as an indicator of paradigm development in pharmacy's academic subdisciplines. Res Social Adm Pharm. 2012;8(5):443-454. doi: 10.1016/j.sapharm.2011.11.005

3. Klassen RM, Tze VMC. Teachers' self-efficacy, personality, and teaching effectiveness: a meta-analysis. Educ Res Rev. 2014;12(1):59-76. doi: 10.1016/j.edurev.2014.06.001

4. Lyon AR, Cook CR, Brown EC, Locke J, Davis C, Ehrhart M, AaronsGA. Assessing organization implementation context in thd education sector: Confirmatory factor analysis of measure of implementation leadership, climate and citizenship. Implement Sci. 2018;13(1): Article 5. doi: 10.1186/s13012-017-0705-6

5. Singh RK, Chaudhary P.Measuring impact of organizational culture on creativity in higher education. Qual Assurance Educ. 2018;26(4):410-422. doi: 10.1108/QAE-04-2018-0041

6. Tierney WG. Faculty productivity and academic culture. In: W.G. Tierney (Ed.). Faculty Productivity: Facts, Figures, andlssues. 2019. New York: Routledge; pp.39-53.

7. Gerstenber D. As the twig is bent: faculty development. ADE Bull. 1981;n67(1):19-21. doi: 10.31274/rtd-1808135189.

8. McCarty H. From deadwood to greenwood: Working with burned out staff. J Staff Develop. 1993;14(1):42-46.

9. Allen L. The nursing shortage continues as faculty shortage grows. Nurs Econ. 2008;26(1):3-50.

10. Desselle SP, Zgarrick DP. How CEO deans in academic pharmacy describe and manage high-performing and lowperforming faculty. Innov Pharm. 2020;11(1): Article 4. doi: 10.24926/iip.v11i1.2236

11. Osborne CA. Followership and leadership: promoting unity in academia. J Vet Med Educ. 2011;38(4):349-352. doi: 10.3138/jvme.38.4.349

12. Gamze K. Toxic behaviors in workplace: examining the effects of the demographic factors on faculty members' perceptions of organizational toxicity. Int/ J Res Educ Sci. 2019;5(1):272-282.

13. Dillman DA, Smyth JD, Christian LM. Internet, Mail, and Mixed-mode Surveys-The

14. Tailored Design Method, $3^{\text {rd }}$ ed. Hoboken: John Wiley \& Sons, Inc.; 2009

15. Qualtrics. (2019) Provo, Utah. https://www.qualtrics.com.

16. IBM Corp. 2017. IBM SPSS Statistics for Windows, Version 25.0. Armonk, NY.

17. Hardigan PC, Popovici I, Carvajal MJ. Response rate, response time, and economic costs survey. Res Social Adm Pharm. 2016;21(1):141-148. doi: 10.1016/j.sapharm.2015.07.003 
18. AACP. (2019). 2018-19 AACP Profile of Pharmacy Faculty. https://www.aacp.org/system/files/2019-02/PPF1819final.pdf. Accessed June 19, 2021

19. Toma DJ. Expanding peripheral activities, increasing accountability demands and reconsidering governance in US higher education, Higher Educ Res Develop. 2007;26(1):57-72. doi: 10.1080/07294360601166810

20. Sorinola OO, Thistlethwaite J, Davies D, Peile E. Faculty development for educators: A realist evaluation. Adv Health Sci Educ. 2015;20(3):385-401. doi: 10.1007/s10459-0149534-4

21. Abramo G, Cicero T, Ciriaco AD. The impact of unproductive and top researchers on overall university performance. $J$ Informatics. 2013;7(1):166-175. doi: 10.1016/j.joi.2012.10.006

22. Wood M, Johnsrud LK. Post-tenure review: What matters to faculty. Rev Higher Educ. 2005; 23(3):393-420. doi: 10.1353/rhe.2005.0029

23. Nikolioudakis N, Tsikliras AC, Somarakis S, Stergious KI. Tenure and academic deadwood. Ethics Sci Environ Politics. 2015;15(1):87-93. doi: 10.3354/esep00166

24. Schumann DW, Peters J, Olsen T. Co-creating value in teaching and learning centers. New Direct Teach Learn. 2013;133:21-32. doi: 10.1002/tl.20043

25. Fountain J, Newcomer KE. Developing and sustaining effective faculty mentoring programs. J Public Aff Educ. 2016;22(4), 483-506. doi: 10.1080/15236803.2016.12002262

26. Desselle SP, Andrews B, Liu J, Raja GL.The scholarly productivity and work environments of academic pharmacists. Res Social Adm Pharm. 2018;14(8):727-735. doi: 10.1016/j.sapharm.2017.09.001

27. Schmidt CE, McNulty B, Howard-Baptiste H, Harvey J. Perspective about how to define and use collegiality in higher education. Int/ J Kinesiol Higher Educ. 2017;1(1):2834. doi: 10.1080/24711616.2016.1277674
28. Schimmel T, Johnston PC, Stasio M. Can "collegiality" be measured? Further validation of a faculty assessment model of discretionary behaviors. Res Higher Educ J. 2013;21(8):1-7.

29. Way F, Morgan AC, Larremore, DB, Clauset A. Productivity, prominence, and the effects of academic environment. Proc Natl Acad Sciences US. 2019;116(22):10629-10733. doi: $10.1073 /$ pnas.1817431116

30. Chen YF, Zoega G. Life-cycle, effort and academic deadwood. Birbeck Research Institute Online. Working Paper. 2010. London: Birbeck College. https://eprints.bbk.ac.uk/7545/, Accessed June 19, 2021.

31. Carmody KA. An academic relative value unit system. Do transparency, consensus, and accountability work? West J Emerg Med. 2019;20(6):939-947. doi: 10.5811/westjem.2019.8.43832

32. O'Meara KA, Lennartz CJ, Kuvaeva A, Jaeger A, Mirsa J. Department conditions and practices associated with faculty workload satisfaction and perceptions of equity. $J$ Higher Educ. 2019; 90(5):744-772. doi: 10.1080/00221546.2019.1584025

33. Lee MS. Evaluating how faculty spend their time at a private research university. [Ed.D dissertation]. University of Southern California; 2012.

34. Bland CJ, Center BA, Finstad DA.The impact of appointment type on the productivity and commitment of full-time faculty in research and doctoral institutions. J Higher Educ. 2006;77(1):89-123. doi: 10.1080/00221546.2006.11778920

35. QuraishiU, Hussain I, Ali Syed M, Rahman, F. Faculty satisfaction in higher education: A TQM approach. J College Teach Learn. 2010;7(6):31-34. doi: 10.19030/tlc.v7i6.127

36. Gmelch WH, Roberts D, Ward K, Hirsch S. A retrospective review of department chairs: Lessons learned. The Dept Chair. 2017;28(1):1-4. doi: 10.1002/dch.30140

37. Gmelch WH, Ward K, Roberts D, Ezeh CC. The stressed-out swivel chair. The Dept Chair. 2018;28(3):9-11. doi: 10.1002/dch.30172 
Table 1. Demographic and institutional characteristics of respondents $(n=463)$

\begin{tabular}{|c|c|}
\hline Characteristic & $N(\%)$ \\
\hline \multicolumn{2}{|l|}{ Sex } \\
\hline Male & $184(39.7 \%)$ \\
\hline Female & $261(56.4 \%)$ \\
\hline Prefer not to answer & $18(3.2 \%)$ \\
\hline \multicolumn{2}{|l|}{ Discipline } \\
\hline Biological Sciences & $23(5.0 \%)$ \\
\hline Experiential Education & $24(4.2 \%)$ \\
\hline Medicinal chemistry & $14(3.0 \%)$ \\
\hline Pharmaceutics & $28(6.0 \%)$ \\
\hline Pharmacology/toxicology & $29(6.3 \%)$ \\
\hline Pharmacy Practice & $264(57.0 \%)$ \\
\hline Social/Behavioral Pharmacy & $72(15.6 \%)$ \\
\hline Other & $9(1.9 \%)$ \\
\hline \multicolumn{2}{|l|}{ Academic rank } \\
\hline Instructor & $5(1.1 \%)$ \\
\hline Assistant professor/clinical assistant professor & $146(31.5 \%)$ \\
\hline Associate professor/clinical associate professor & $149(32.2 \%)$ \\
\hline Professor/clinical professor & $151(32.6 \%)$ \\
\hline Other & $12(2.6 \%)$ \\
\hline \multicolumn{2}{|l|}{ Tenure status } \\
\hline Non-tenure track & $249(53.8 \%)$ \\
\hline Tenure track, but not tenured & $50(10.8 \%)$ \\
\hline Tenured & $144(31.1 \%)$ \\
\hline Other & $20(3.5 \%)$ \\
\hline \multicolumn{2}{|l|}{ Administrative title/Position* } \\
\hline None & $222(47.9 \%)$ \\
\hline Coordinator/Director & $91(19.7 \%)$ \\
\hline Department Chair/Vice-chair & $58(12.5 \%)$ \\
\hline Assistant/Associate dean & $72(15.6 \%)$ \\
\hline Dean & $20(4.3 \%)$ \\
\hline Other & $12(2.6 \%)$ \\
\hline \multicolumn{2}{|l|}{ Supervises other faculty (previously or currently) } \\
\hline Yes & $123(26.6 \%)$ \\
\hline No & $340(73.4 \%)$ \\
\hline \multicolumn{2}{|l|}{ Ownership/Governance of institution where employed } \\
\hline Public & $249(53.8 \%)$ \\
\hline Private, not-for-profit & $169(36.5 \%)$ \\
\hline Private, for-profit & $45(9.7 \%)$ \\
\hline \multicolumn{2}{|l|}{ Mission of institution where employed } \\
\hline Teaching & $215(46.4 \%)$ \\
\hline Balanced & $154(33.2 \%)$ \\
\hline Research & $94(20.3 \%)$ \\
\hline \multicolumn{2}{|l|}{ Years as a faculty member } \\
\hline $0-10$ years & $226(48.8 \%)$ \\
\hline $11-20$ years & $128(27.6 \%)$ \\
\hline 21 or more years & $103(22.2 \%)$ \\
\hline
\end{tabular}

*Totals slightly exceed 463 , as respondents were asked to select all that apply. 
Table 2. Responses to questions regarding what constitutes deleterious faculty or. "academic deadwood" at their institution, and differences in those responses by personal and institutional variables $(N=463)$

What, in your mind, constitutes a faculty being a "deadwood" faculty member?

\begin{tabular}{|c|c|c|c|c|}
\hline & $\begin{array}{l}\text { Not all defining of } \\
\text { "deadwood" }\end{array}$ & $\begin{array}{l}\text { Somewhat what } \\
\text { I consider to be } \\
\text { "deadwood" }\end{array}$ & $\begin{array}{l}\text { Very much what I } \\
\text { consider to be } \\
\text { "deadwood" }\end{array}$ & Subgroup Differences $p \leqq 0.01^{a}$ \\
\hline \multicolumn{5}{|l|}{ Little or no productivity in scholarship } \\
\hline & $8.9 \%$ & $43.8 \%$ & $47.3 \%$ & Mission, Tenure Status \\
\hline \multicolumn{5}{|l|}{ Conducts little to no teaching } \\
\hline & $6.7 \%$ & $25.3 \%$ & $68.0 \%$ & \\
\hline \multicolumn{5}{|l|}{ Teaching is of low quality } \\
\hline & $2.6 \%$ & $17.9 \%$ & $79.5 \%$ & Public/private, Mission, Discipline \\
\hline $\begin{array}{l}\text { Fails to effectively participate on } \\
\text { Institutional committees }\end{array}$ & $5.0 \%$ & $33.3 \%$ & $61.8 \%$ & Tenure Status, Years on Faculty \\
\hline $\begin{array}{l}\text { Fails to effectively engage in their } \\
\text { external scientific/professional communities }\end{array}$ & $11.9 \%$ & $48.4 \%$ & $39.7 \%$ & Supervisor, Years on Faculty \\
\hline $\begin{array}{l}\text { Demonstrates poor collegiality / citizenship } \\
\text { Behaviors }\end{array}$ & $3.2 \%$ & $20.7 \%$ & $76.0 \%$ & Public/private, Mission \\
\hline
\end{tabular}

a Mission = Self-reported teaching vs. Research and Balanced institutional categories; Tenure Status = On or not on tenure track; Public/private = Public or private institution; Years on Faculty = 1-10 years vs. 11-20 years, vs. $>20$ years; Supervisor= Self-reported supervisor of other faculty; Discipline = Basic sciences (collapsed from medicinal chemistry, biological sciences, pharmaceutics, and pharmacology/toxicology, vs. social/administrative sciences vs. pharmacy practice [including experiential]) 
Table 3. Responses to questions on what is being done, what should be done regarding deleterious faculty or "academic deadwood" at their institutions, and differences in these responses ( $N=463)$

Things that respondents report are CURRENTLY BEING DONE regarding "deadwood" faculty at their institutions

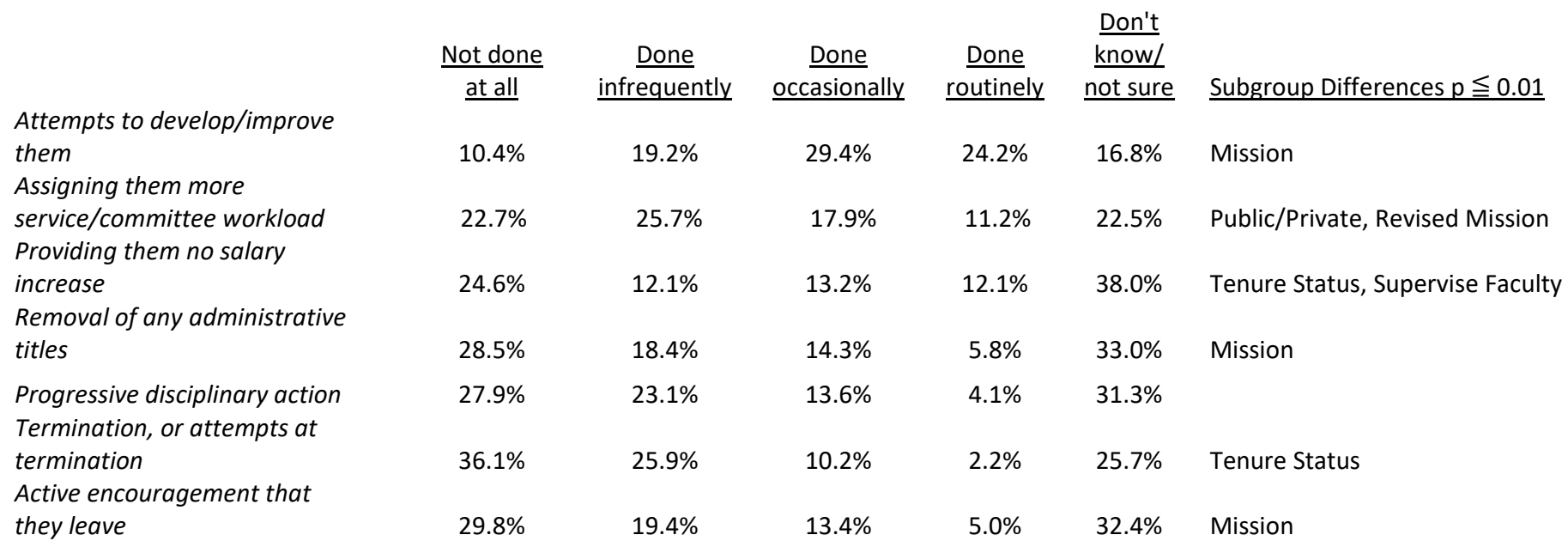

Things respondents feel SHOULD BE DONE regarding "Deadwood" faculty

\begin{tabular}{|c|c|c|c|c|c|}
\hline & $\frac{\text { Not done at }}{\text { all }}$ & $\stackrel{\text { Done }}{\text { infrequently }}$ & $\begin{array}{c}\text { Done } \\
\text { occasionally }\end{array}$ & $\begin{array}{l}\text { Done } \\
\text { routinely }\end{array}$ & Subgroup Differences $p \leqq 0.01$ \\
\hline $\begin{array}{l}\text { Attempts to develop/improve } \\
\text { them }\end{array}$ & $1.3 \%$ & $1.5 \%$ & $16.6 \%$ & $80.6 \%$ & Discipline \\
\hline $\begin{array}{l}\text { service/committee workload } \\
\text { Providing them no salary }\end{array}$ & $13.8 \%$ & $22.5 \%$ & $41.3 \%$ & $22.5 \%$ & Discipline \\
\hline increase & $9.7 \%$ & $10.4 \%$ & $29.6 \%$ & $50.3 \%$ & Public/Private, Mission \\
\hline $\begin{array}{l}\text { Removal of any administrative } \\
\text { titles }\end{array}$ & $5.4 \%$ & $19.7 \%$ & $34.8 \%$ & $40.2 \%$ & \\
\hline Progressive disciplinary action & $5.0 \%$ & $16.0 \%$ & $35.2 \%$ & $43.8 \%$ & \\
\hline $\begin{array}{l}\text { Termination, or attempts at } \\
\text { termination } \\
\text { Active encouragement that }\end{array}$ & $6.5 \%$ & $31.7 \%$ & $36.5 \%$ & $25.3 \%$ & Discipline \\
\hline they leave & $11.9 \%$ & $26.8 \%$ & $32.6 \%$ & $28.7 \%$ & Tenure Status, Discipline \\
\hline
\end{tabular}

a Mission = Self-reported teaching vs. Research and Balanced institutional categories; Tenure Status = On or not on tenure track; Public/private $=$ Public or private institution; Years on Faculty $=1-10$ years vs. $11-20$ years, vs. $>20$ years; Supervisor= Self-reported supervisor of other faculty; Discipline = Basic sciences (collapsed from medicinal chemistry, biological sciences, pharmaceutics, and pharmacology/toxicology vs. social/administrative sciences vs. pharmacy practice [including experiential\}) 